\title{
Hepatocellular adenoma among adult survivors of childhood and young adult cancer
}

\author{
Emily S. Tonorezos, MD MPH ${ }^{1,2}$, Dana Barnea, MD¹, Ghassan K. Abou-Alfa, MD ${ }^{1,2}$, \\ Jacqueline Bromberg, MD PhD ${ }^{1}$, Michael D'Angelica, MD', ${ }^{1,2}$, Charles A. Sklar, MD ${ }^{1}$, Jinru \\ Shia, $\mathbf{M D}^{1,2}$, and Kevin C. Oeffinger, $\mathbf{M D}^{1}$ \\ ${ }^{1}$ Memorial Sloan Kettering, New York, NY \\ ${ }^{2}$ Weill Cornell Medical College, New York, NY
}

\begin{abstract}
Hepatocellular adenoma (HCA) is a rare benign epithelial neoplasm with potential for hemorrhage, rupture, or malignant transformation. Reported annual incidence of HCA is approximately $1 / 1,000,000$. We identified twelve cases of HCA among adults with a history of childhood or young adult cancer. The most common cancer diagnosis was leukemia $(\mathrm{N}=4)$. Five had undergone allogeneic hematopoietic stem cell transplant with total body irradiation. All eleven females had prior estrogen therapy; the male case was hypogonadal. This report suggests childhood and young adult cancer survivors may be at increased risk for HCA, but further investigation is needed.
\end{abstract}

\section{Keywords}

childhood cancer; hepatocellular adenoma; hepatoma; survivor

\section{INTRODUCTION}

Hepatocellular adenoma (HCA) is a rare and incompletely understood benign epithelial tumor. Among women who have never used contraceptives, the incidence of HCA is estimated at approximately 1 per 1,000,000 person-years; with oral contraceptives, the annual incidence is approximately 30 per 1,000,000. Among men, the incidence is even lower. ${ }^{1}$ In addition to oral contraceptive or androgen use, other risk factors include type I and III glycogen storage diseases, external androgens, anti-epileptic drugs, and nonalcoholic fatty liver disease. ${ }^{1-5}$ In the general population, the most common HCA subtype is steatotic, reflecting hepatocyte nuclear factor $1 \mathrm{~A}$ inactivation. ${ }^{6}$ The risks of rupture or malignant transformation of HCA are substantial and may be increased during pregnancy or with ongoing use of oral contraceptives. As a result of these risks, HCA is usually managed with resection, embolization, or close radiographic follow-up. ${ }^{7}$

Corresponding author: Emily S. Tonorezos, MD MPH, Adult Long Term Follow-Up Program, Memorial Sloan Kettering, 485 Lexington Avenue, $2^{\text {nd }}$ Floor, New York, NY 10017, tonoreze@ mskcc.org, Tel: 646-888-8080; Fax: 929-321-1518. 
Childhood cancer survivors are at risk for a small number of hepatic late effects. Most notably, hepatic hemochromatosis may be acquired due to red blood cell transfusion requirements during treatment. ${ }^{8}$ In addition, survivors treated before routine screening of the blood supply are at risk for hepatitis $\mathrm{C}$ infection. Finally, a possible increased risk of focal nodular hyperplasia (FNH) has been identified among childhood cancer survivors, although the literature is sparse. ${ }^{9} \mathrm{An}$ increased risk for hepatocellular adenoma has not been described.

\section{METHODS}

Following approval by the Institutional Review Board at Memorial Sloan Kettering (MSK), a comprehensive search of the medical record was initiated. Pathology reports, visit notes, histology codes, and billing diagnosis codes were searched for the terms "hepatic adenoma," "hepatocellular adenoma," "hepatobiliary adenoma," "hepatoma," or "hepadenoma." Once patients with HCA were identified, demographics, cancer diagnosis, and cancer treatment variables were collected from the medical chart. Those with slides or tissue available were re-reviewed by a gastrointestinal pathologist at MSK (JS).

Cases were compared to hepatocellular adenoma from the general population using literature review. However, due to the small number of cases and lack of an appropriate control (nonsurvivor) population, no attempts at statistical analysis or comparisons were made.

\section{RESULTS}

Among adult survivors of childhood and young adult cancer followed at this large U.S. cancer center, twelve cases of hepatocellular adenoma (HCA) were confirmed; seven patients $(58 \%)$ had more than one adenoma. Six cases were initially identified from the 1,296 patients followed in the Adult Long-Term Follow-Up Program at MSK and were under 18 at the time of primary cancer diagnosis and treatment; the remainder was retrieved from the medical records of the 50,768 patients who were diagnosed with cancer before the age of 40 and seen in any setting at MSK between 1982 and 2015. Seven of twelve identified cases had more than one HCA, with median size of $3.9 \mathrm{~cm}$ (range, 1.8 to $8.2 \mathrm{~cm}$ ).

\section{Clinical characteristics and outcomes}

Among these twelve childhood and young adult cancer survivors with hepatocellular adenoma, only one patient was male (Table 1). Importantly, this patient also had a history of hematopoietic stem cell transplant for acute myelogenous leukemia and was hypogonadal. At the time of his biopsy, he was being treated with androgen replacement, a known risk factor for hepatocellular adenoma. Due to the clinical circumstances, it was not felt appropriate to discontinue androgen replacement. Among the eleven female survivors with hepatocellular adenoma, all had a history of current or prior treatment with estrogen and progesterone. Eight of twelve patients (67\%) had hypothyroidism and two (17\%) were taking anti-epileptic drugs.

The most common cancer diagnosis was leukemia $(\mathrm{N}=4 ; 33 \%)$. Five survivors $(42 \%)$ had undergone allogeneic hematopoietic stem cell transplant with total body irradiation (TBI) as 
part of their preconditioning regimen. One patient, a hematopoietic stem cell transplant survivor with a history of TBI, appears to have hepatocellular adenomatosis (more than 10 adenoma) and is being followed by both internal medicine and hepatobiliary surgery. No patient was known to have a cancer predisposition syndrome. The majority of patients with HCA were normal weight; median body mass index at the time of HCA diagnosis was 22.2 $\mathrm{kg} / \mathrm{m}^{2}$ (range, $17.6-31.0 \mathrm{~kg} / \mathrm{m}^{2}$ ).

\section{Pathology review}

Pathology reports of all 12 cases were reviewed. In addition, slides of 6 cases were available and all 6 were re-examined at the time of this study. The results of slide re-examination were concordant with the pathology reports in all 6 cases. The diagnosis of hepatocellular adenoma was confirmed in all cases. Upon histological assessment, 4 of the 12 adenomas were subtyped as inflammatory, 3 as steatotic, and 5 as unclassified, non-inflammatory (Figure 1). The non-neoplastic liver was normal in 10 cases, and showed steatosis without fibrosis in 2 cases.

\section{Follow-up}

Only two patients (17\%) were monitored radiographically without other intervention following biopsy. Seven patients (58\%) underwent hepatic resection, of which four had residual adenoma following surgery and continue to be monitored with MRI. Three (25\%) underwent transarterial embolization (without chemotherapy) via interventional radiology. Two female patients had their hormone replacement formulation changed to transdermal in an effort to reduce hepatic estrogen exposure; in other patients, estrogen and progesterone were discontinued. No patient has subsequently been found to have hepatocellular carcinoma (with a median follow - up of 8.5 years, range, 7.1-14.7 years) and no patient has died.

\section{DISCUSSION}

We describe herein twelve cases of hepatocellular adenoma (HCA) among adult survivors of childhood and young adult cancer followed at a large U.S. cancer center. In this setting, HCAs were found to be large, often multiple, and primarily inflammatory, without steatosis. No prior study has identified an increased risk for hepatocellular adenoma following childhood and young adult cancer therapy.

As in other populations, the majority of our patients with HCA were female with a history of estrogen therapy. ${ }^{1}$ Yet, the mechanism by which estrogen increases the risk of HCA in a non-cancer setting is poorly understood. ${ }^{10}$ Furthermore, young women who are postmenopausal as a result of their cancer treatment have strong indications for estrogen and progesterone replacement and may not be able to easily discontinue therapy. ${ }^{11}$ Screening for HCA among young hypogonadal cancer survivors may be warranted, but further study of this question is needed.

Some aspects of our case series suggest that new mechanisms may be involved in HCA incidence in this population. One third of these HCA cases were of the inflammatory subtype, which is not the predominant subtype in the general population. ${ }^{6}$ Typically, the 
inflammatory subtype is associated with gain of function IL-6 signal transducer (IL6ST;gp130) and STAT3 mutations. ${ }^{9}$ Although persistent activation of this signaling pathway is associated with tumorigenesis, ${ }^{12}$ other work suggests that HCA of the inflammatory subtype do not progress to carcinoma. ${ }^{6}$ Therefore, whether HCA among cancer survivors will be at increased or decreased risk for malignant transformation remains to be determined.

Because only cases were captured in thisbrief report, and a suitable control group that would have undergone routine imaging has been difficult to identify, comparisons are limited and incidence or prevalence could not be calculated.

Nonetheless, a small number of clinical and treatment variables were found to be common among survivors with HCA: (1) female gender; (2) history of stem cell transplant; (3) hormone replacement therapy; and (4) total body irradiation. Importantly, HCA has the potential to be extremely morbid; ten of the twelve identified survivors required major intervention (surgery or embolization) and four of these were left with residual adenoma requiring ongoing monitoring. Thus, further study to clarify risk, mechanism, and modifying factors in this population is warranted.

\section{Acknowledgments}

None.

Funding sources: This work was supported by the National Cancer Institute (K05CA160724, R01CA187397, P30CA008748), and the Meg Berté Owen Foundation.

\section{Abbreviations}

HCV Hepatocellular adenoma

FNH Focal nodular hyperplasia

MSK Memorial Sloan Kettering

\section{References}

1. Rooks JB, Ory HW, Ishak KG, et al. Epidemiology of hepatocellular adenoma. The role of oral contraceptive use. JAMA. Aug 17; 1979 242(7):644-648. [PubMed: 221698]

2. Lee PU, Roberts LR, Kaiya JK, Lee CU. Hepatic adenomas associated with anti-epileptic drugs: a case series and imaging review. Abdominal imaging. Apr; 2010 35(2):208-211. [PubMed: 19283429]

3. Lefkowitch JH, Antony LV. The Evolving Role of Nonalcoholic Fatty Liver Disease in Hepatic Neoplasia: Inflammatory Hepatocellular Adenoma in a Man with Metabolic Syndrome. Seminars in liver disease. Aug; 2015 35(3):349-354. [PubMed: 26378649]

4. Oterdoom LH, Verweij KE, Biermann K, Langeveld M, van Buuren HR. Hepatocellular Adenomas and Carcinoma in Asymptomatic, Non-Cirrhotic Type III Glycogen Storage Disease. Journal of gastrointestinal and liver diseases : JGLD. Dec; 2015 24(4):515-518. [PubMed: 26697579]

5. Gupta S, Naini BV, Munoz R, et al. Hepatocellular Neoplasms Arising in Association With Androgen Use. The American journal of surgical pathology. Apr; 2016 40(4):454-461. [PubMed: 26685086] 
6. Zucman-Rossi J, Jeannot E, Nhieu JT, et al. Genotype-phenotype correlation in hepatocellular adenoma: new classification and relationship with HCC. Hepatology (Baltimore, Md). Mar; 2006 43(3):515-524.

7. Dokmak S, Paradis V, Vilgrain V, et al. A single-center surgical experience of 122 patients with single and multiple hepatocellular adenomas. Gastroenterology. Nov; 2009 137(5):1698-1705. [PubMed: 19664629]

8. Ruccione KS, Wood JC, Sposto R, Malvar J, Chen C, Freyer DR. Characterization of transfusionderived iron deposition in childhood cancer survivors. Cancer epidemiology, biomarkers \& prevention : a publication of the American Association for Cancer Research, cosponsored by the American Society of Preventive Oncology. Sep; 2014 23(9):1913-1919.

9. Sudour H, Mainard L, Baumann C, Clement L, Salmon A, Bordigoni P. Focal nodular hyperplasia of the liver following hematopoietic SCT. Bone marrow transplantation. Jan; 2009 43(2):127-132. [PubMed: 18806834]

10. Liau SS, Qureshi MS, Praseedom R, Huguet E. Molecular pathogenesis of hepatic adenomas and its implications for surgical management. Journal of gastrointestinal surgery : official journal of the Society for Surgery of the Alimentary Tract. Oct; 2013 17(10):1869-1882. [PubMed: 23835731]

11. Tonorezos ES, Hudson MM, Edgar AB, et al. Screening and management of adverse endocrine outcomes in adult survivors of childhood and adolescent cancer. The lancet Diabetes \& endocrinology. Jul; 2015 3(7):545-555. [PubMed: 25873569]

12. Gao SP, Mark KG, Leslie K, et al. Mutations in the EGFR kinase domain mediate STAT3 activation via IL-6 production in human lung adenocarcinomas. The Journal of clinical investigation. Dec; 2007 117(12):3846-3856. [PubMed: 18060032] 

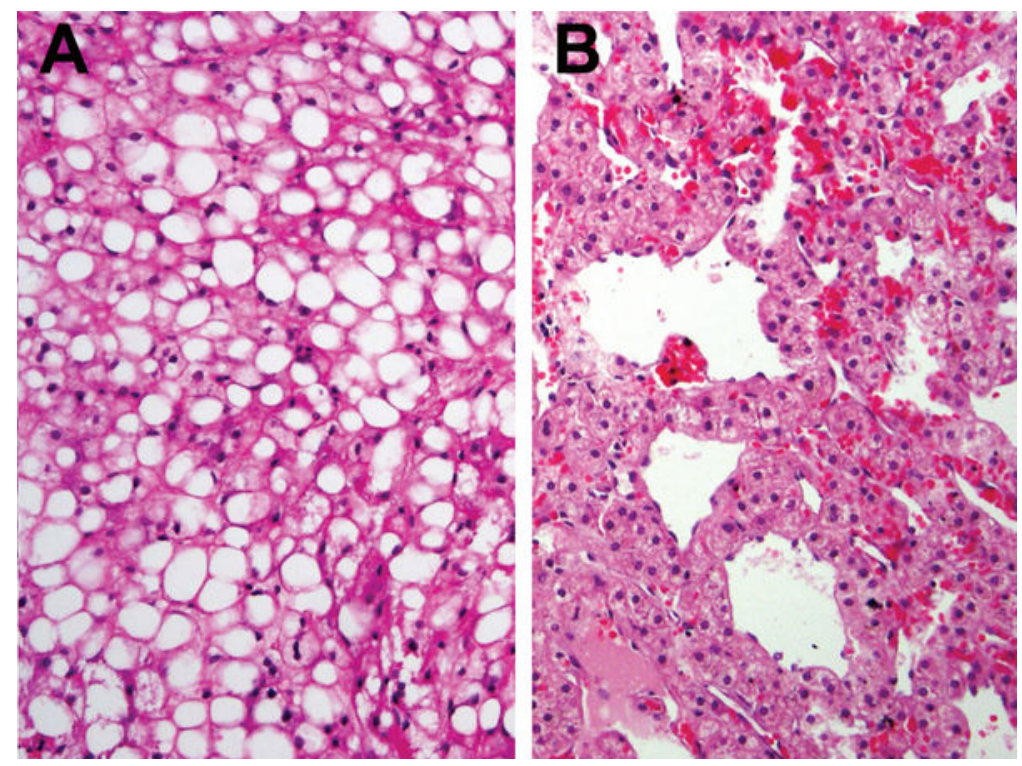

Figure 1.

Representative pathology from two cases of hepatocellular adenoma with steatotic (panel A) and inflammatory (panel B) features. 


\section{Table 1}

Demographics and cancer treatment variables for 12 childhood and young adult cancer survivors diagnosed with hepatocellular adenoma.

\begin{tabular}{|c|c|}
\hline Characteristic & $\mathrm{N}=12$ \\
\hline Females (number, \%) & $11(92)$ \\
\hline Body mass index, in $\mathrm{kg} / \mathrm{m}^{2}$ (median, range) & $22.2(17.6-39.8)$ \\
\hline Hypothyroid & $8(66)$ \\
\hline Anti-seizure medication & $2(17)$ \\
\hline Estrogen/progesterone replacement therapy, among 11 females (number, \%) & $11(100)$ \\
\hline Testosterone replacement therapy, among 1 male (number, \%) & $1(100)$ \\
\hline Age at primary cancer diagnosis, in years (median, range) & $12.5(3-33)$ \\
\hline Age at diagnosis of hepatocellular adenoma, in years (median, range) & $31(21-50)$ \\
\hline Time since from cancer diagnosis to adenoma detection, in years (median, range) & $8.5(4-14)$ \\
\hline \multicolumn{2}{|l|}{ Cancer diagnosis (number, \%) } \\
\hline Leukemia & $4(33)$ \\
\hline Thyroid carcinoma & $2(17)$ \\
\hline Brain tumor & $2(17)$ \\
\hline Cervical cancer & $1(8)$ \\
\hline Lymphoma & $1(8)$ \\
\hline Melanoma & $1(8)$ \\
\hline Sarcoma & $1(8)$ \\
\hline \multicolumn{2}{|l|}{ Decade of treatment for childhood cancer (number, \%) } \\
\hline $1980-1989$ & $4(33)$ \\
\hline 1990-1999 & $4(33)$ \\
\hline $2000-2009$ & $4(33)$ \\
\hline Total body irradiation (number, \%) & $5(42)$ \\
\hline Craniospinal radiotherapy (number, \%) & $2(17)$ \\
\hline
\end{tabular}

